УДК 8

DOI 10.31483/r-21464

\title{
И.А. Басова
}

\section{ХАРАКТЕРИСТИКА И ТИПОЛОГИЯ РЕФЕРАТОВ КАК ПРОДУКТОВ РЕФЕРИРОВАНИЯ}

Аннотация: в данной статье обозначаются современные тенденщии в понимании реферата как типа текста, уточняется понятие «реферат» как продукт реферирования, рассматриваются отличия реферата от аннотации. Автором приводится типология рефератов и основные требования, предъявляемые к их составлению и оцениванию. В данной работе проводится разграничение информативных и индикативных рефератов. Выделяются монографический, сводный, аспектный, фрагментный, целевой, общий и анкетный рефеpaты, а также рассматриваются особенности каждого из представленных типов.

Ключевые слова: реферат, аннотация, информативный реферат, индикативный реферат, монографический общий реферат.

\section{CHARACTERISTICS AND TYPOLOGY OF SUMMARIES AS PRODUCTS OF SUMMARIZING}

Abstract: in this article, modern trends in the understanding of the summary as a type of text are indicated, the concept of "summary" as a product of summarizing is clarified, differences of the summary from the abstract are examined. The author gives the typology of summary and the main requirements for their compilation and evaluation. In this work informative and indicative summaries are distinguished. The monographic, summary, aspect, fragment, target, general and questionnaire summaries are singled out, and also the features of each of the presented types are considered.

Keywords: summary, abstract, informative summary, indicative summary, monographic general summary. 
Говоря об определении понятия «реферат», нельзя не отметить, что несмотря на многочисленные исследования реферата как информативного жанра, единого определения этого понятия нет, что, прежде всего, связано с его многофункциональностью.

В настоящее время наметились две основные тенденции в понимании реферата как типа текста:

1. В современной информационной деятельности реферат рассматривается как краткое изложение в письменном виде содержания книги, учения, научной проблемы, результатов научного исследования, а также доклад на определенную тему, освещающий ее на основе обзора литературы и других источников. Иными словами, под рефератом понимается результат реферирования.

2. В средних и высших учебных заведениях зачастую под рефератом в основном понимается творческая работа учащегося или студента, в которой на основании краткого письменного изложения и оценки различных источников проводится самостоятельное исследование определенной темы, проблемы.

Учитывая сложившееся в школе и вузе представление о реферате как о самостоятельной творческой работе, основанной на изучении различных первоисточников, можно выделить следующие отличия учебного реферата от реферата, понимаемого как результат реферирования:

- учебный реферат создается на основе изучения нескольких первоисточников, тогда как реферирование проводится на основе одного исходного текста;

- учебный реферат является «первичным текстом», результатом творческой переработки текстов первоисточников, в то время как результат реферирования представляет собой «вторичный текст», кратко излагающий содержание реферируемой работы;

- тема учебного реферата выбирается на основании самостоятельных творческих изысканий учащегося и преподавателя, а о теме продукта реферирования говорить не имеет смысла, поскольку она не может быть самостоятельной и независимой и всегда должна быть посвящена тому, о чем повествует исходный первичный текст; 
- цель, заявленная в учебном реферате, ставится самостоятельно, тогда как целью реферирования может быть только краткая и точная передача содержания исходного текста;

- в учебном реферате подразумевается и приветствуется выражение учащимся или студентом собственного отношения к положениям первоисточников или оценка излагаемого текста, в то время как реферирование исключает оценку и выражение личной точки зрения автора.

Таким образом, одно название - два разных типа текста (творческая работа и результат реферирования). Мы рассмотрим различные определения понятия «реферат» как продукта реферирования.

Буданова Т.А. даёт следующее определение: «Реферат (от латинского referre - сообщать, докладывать) - это сокращённое содержание печатного произведения с основными фактическими данными. Реферат представляет собой объективное, лишённое эмоций сообщение информации первоисточника на основе её смысловой переработки. Он акцентирует внимание на новых сведениях и определяет целесообразность обращения к первоисточнику» [2, с. 27].

Такая трактовка понятия «реферат» широко распространена, однако достаточно узка. Очевидно, что речь идёт о рефератах специальных текстов определённой сферы деятельности с целью охвата большого количества фактической информации. Более того, речь идёт исключительно о печатных текстах.

Идрисов Ф.Ф. определяет реферат как краткое точное изложение содержания документа, включающее основные фактические сведения и выводы, без дополнительной интерпретации или критических замечаний автора реферата [6, c. 24-26]. Одновременно другие исследователи считают комментарии референта необходимой составляющей реферата. М.С. Корнеева даёт следующее определение: «Реферат представляет собой краткое изложение в письменном виде или в форме публичного доклада содержания научного труда / трудов и/или литературы по теме с раскрытием их основного содержания по всем затронутым вопросам, сопровождаемое оценкой и выводами референта» [Корнеева, 1993, с. 77]. Исследователь отмечает, что референт должен дать читателю объективное 
представление о характере освещаемой работы, изложить наиболее существенные моменты её содержания. Реферат, как подчёркивает исследователь, даёт описание первичного документа, оповещает о выходе в свет и о наличии соответствующих первичных документов, также он является источником для получения справочных данных и самостоятельным средством научной информации. Цель реферата - дать читателю относительно полное представление о затронутых в первоисточнике вопросах.

Очевидно, что в данном случае речь идёт о реферировании текстов в научных целях. Если речь идёт об обучении студентов языковых вузов/факультетов реферированию текстов как профессиональной, так и любой другой тематики, наибольший интерес представляют следующие трактовки понятия «реферат».

С.Л. Бурлакова определяет реферат как «самостоятельное письменное речевое произведение, создаваемое на выход с ориентацией на читателя. Оно носит репродуктивно-продуктивный характер, характеризуется большой степенью компрессии информации исходного текста, абстрагирования, обобщения и переконструирования композиционно-смысловой структуры первоисточника, достаточной степенью выраженности оценочного характера, а также связностью и завершённостью» [3, с. 39].

Гаврилов Л.А. даёт следующее определение: «Реферат - это семантически адекватное, ограниченное малым объёмом и вместе с тем возможно полное изложение основного содержания первичного документа, отличающееся постоянством структуры и предназначенное для выполнения разнообразных информационно-коммуникативных функций при использовании его читателями различных категорий» [5, с. 46] Иными словами, реферат - это творчески обработанное, логически переструктурированное в синтаксическом и языковом плане произведение, передающее подлинную, неискажённую, ценностнозначимую информацию.

Таким образом, реферат как продукт реферирования - это самостоятельное речевое произведение, создаваемое на выходе с ориентацией на читателя. Оно носит репродуктивно-продуктивный характер и представляет собой 
семантически адекватное изложение основного содержания исходного текста (печатного или аудиотекста), отличающееся постоянством структуры, экономной знаковой оформленностью, большой степенью компрессии исходного текста, абстрагирования, обобщения и переконструирования композиционно-смысловой структуры первоисточника, постоянством лингвистических характеристик, связностью и завершённостью и предназначенное для выполнения разнообразных информационно-коммуникационных функций.

Часто встаёт вопрос о том, чем отличается реферат от аннотации. Сущность обоих процессов (реферирования и аннотирования) заключается в максимальном сокращении объёма источника информации при сохранении его основного содержания. Однако, осуществляя компрессию первоисточника, аннотация и реферат делают это принципиально различными способами. Аннотация лишь перечисляет вопросы, которые освещены в первоисточнике, не раскрывая самого содержания этих вопросов. Реферат же не только перечисляет все эти вопросы, но и сообщает существенное содержание каждого из них. Таким образом, по сравнению с аннотированием, реферирование является более полным методом обработки источников информации: если в аннотации приводится лишь краткий перечень рассматриваемых вопросов, то в реферате излагается существо вопросов и приводятся важнейшие выводы [4, с. 32].

На основании анализа исследований, посвящённых реферированию, представляется возможным сделать вывод о том, что преобладающей концепцией типологии рефератов как результатов реферирования, в основу которой положено целевое назначение документов, является деление их на информативные и индикативные. Эта концепция была принята ещё в 1949 году в Париже на Международной конференции по научному реферированию. В дальнейшем она совершенствовалась, развивалась отечественными и зарубежными специалистами. Из отечественных исследований хотелось бы выделить работу В.И. Соловьёва «Реферирование в научно-информационной деятельности и критерий редакторской оценки его содержания и формы», отличающуюся всеобъемлющим характером, 
многогранностью, основанной на большом эмпирическом материале. Из зарубежных исследований следует отметить работы D.B. Cleveland, W.S. Fowler.

Итак, рефераты делятся на информативные и индикативные в зависимости от содержательных и формальных характеристик, от целевой и адресной направленности. В одних случаях требуется реферат, в котором излагалось бы основное содержание первичного текста, в других - реферат, в котором указывалось бы лишь на то, что и как (в какой степени) рассмотрено в том же тексте. Вследствие этого два реферата одного и того же первичного текста получают различную целевую направленность и отличаются по форме изложения информации. Хотя каждый из них выполняет все основные функции, свойственные реферату, а именно информативную, описательную и указательную [1, с. 21], проявляются они по-разному.

В индикативном реферате излагается основное содержание первичного текста. Доминирующим свойством такого реферата является информативность. Он включает фактографическую информацию, то есть служит источником сведений (информации) о фактах, представленных в исходном тексте. Если речь идёт о реферате научного текста, то информативный реферат, помимо всех основных положений оригинала в обобщённом виде, содержит сведения о методике исследования и сфере применения полученных результатов.

В отличие от информативного, индикативный реферат только указывает на основные аспекты содержания первичного текста. Его основные свойства - описательность и указательность. Он характеризует содержание, информационное наполнение первичного документа. В нём называются только такие смысловые аспекты, которые содержат новые полезные сведения. Индикативный реферат даёт характеристику степени их разработанности, новизны, полезности, полноты (подробности) освещения в первоисточнике.

На наш взгляд, умение составлять информативный реферат первично для студентов языковых вузов, поскольку для них важно уметь максимально полно по содержанию, но кратко по форме, передать информацию текстов как профессиональной направленности, так и любого другого характера, при составлении 
докладов, отчётов, написании курсовых и дипломной работ и т. д. В дальнейшем научиться писать индикативные рефераты, навыки выполнения которых необходимы при работе над диссертационным и другими научными исследованиями, будет несложно, имея базу знаний, навыков и умений в написании информативных рефератов.

Важно сказать о том, что концепция В.И. Соловьёва, которую мы берём за основу, представляя типологию рефератов, не ограничивается делением их на информативные и индикативные. В результате аналитико-синтезирующей переработки информации могут быть подготовлены рефераты, которые содержат информацию, относящуюся к одному первоисточнику (ко всему или к какой-либо его части) или к нескольким. Это позволяет выделить рефераты: монографические, обзорные (сводные), аспектные, фрагментные.

Монографический реферат составляется на основе информации, содержащейся в одном первичном документе. Такой реферат называют одноисточниковым.

Сводный реферат (обзорный) содержит сведения из первичных документов по одной теме, изложенные в виде связного текста. Сводные рефераты публикуются обычно в реферативных сборниках.

Acnектный реферат составляется на основе информации не всего первичного документа, а одного или нескольких его смысловых аспектов. Иногда о нём говорят ещё и как о проблемно-ориентированном реферате, имея в виду, что при его составлении ориентируются на отбор информации, относящейся к определённой проблеме, теме, предмету исследования. Если при этом отбор информации проводится не из одного, а из нескольких первоисточников, получается сводный аспектный реферат.

Фрагментный реферат составляется в том случае, когда первичный документ имеет большой объём и к тому же содержит разнопрофильную информацию, и есть потребность в составлении реферата по одному или нескольким структурным элементам (разделам, частям или главам). 
Важное значение для теории и практики реферирования имеет деление рефератов по таким признакам как:

- ориентированность на потребителя информации (целевой и общий рефераты);

- формализация структуры реферата (текстовой и бланочный рефераты, последний может быть анкетным или табличным).

Целевой реферат составляется для удовлетворения определённых, конкретных информационных запросов. Такие рефераты обладают чётким читательским адресом и пригодны для использования в системе дифференцированного распределения информации.

Общчий реферат составляется с учётом отражения в нём всех основных сведений из первичного текста и адресуется тому же кругу потребителей, для которых предназначен первоисточник.

Абсолютное большинство рефератов имеет текстовую форму. Текстовым считается и тот реферат, в котором, наряду со связным текстом, имеются иллюстрации, таблицы и т. д., поскольку текст составляет основу такого реферата.

Анкетный реферат по сути представляет собой ответы на заранее сформулированные вопросы. Роль вопросов играют в одних случаях смысловые аспекты, в других - запросы потребителей информации.

Если вопросы касаются ряда объектов, то иногда становится необходимым расположить ответы в нескольких колонках (графах). Тогда реферат станет табличным.

При всём своём многообразии рефераты обладают некоторыми общими чертами. В реферате не используются рассуждения, материал подаётся в форме описания фактов. Информация излагается точно, кратко, без искажений и субъективных оценок. В тексте реферата не должно быть повторений, исключается использование прямой речи и диалогов. Обязательно включение в текст реферата основных выводов автора первоисточника. 


\section{Список литературы}

1. Перевод и реферирование общественно-политических текстов / сост. Н.П. Беспалова. - М.: Дрофа, 2006.

2. Буданова Т.А. Язык специальности: реферирование. - СПУ, 2003.

3. Бурлакова С.Л. Учебное реферирование как средство развития профессиональной письменной речи студентов: Дис. ... канд. пед. наук. - СПб, 1993.

4. Вейзе А.А. Чтение, реферирование и аннотирование иностранного текста. - М.: Высшая школа, 1985.

5. Гаврилов Л.А. Основы реферирования и аннотирования / Л.А. Гаврилов, Л.К. Латышева. - М., 1981.

6. Идрисов Ф.Ф. Обучение аудированию оригинальной англоязычной разговорной речи при подготовке переводчика-референта: Дис. ... канд. пед. наук. M., 1987.

7. Леонов В.П. О теоретических основах обучения реферированию// Вопросы совершенствования библиографической подготовки кадров. - Ленинград, 1981.

8. Соловьёв В.И. Реферирование в научно-информационной деятельности и критерий редакторской оценки его содержания и формы: Дис. ... канд. филол. наук. - М., 1970.

\section{References}

1. Bespalova, N. P. (2006). Perevod i referirovanie obshchestvenno-politicheskikh tekstov. M.: Drofa.

2. Budanova, T. A. (2003). Iazyk spetsial'nosti. SPU.

3. Burlakova, S. L. (1993). Uchebnoe referirovanie kak sredstvo razvitiia professional'noi pis'mennoi rechi studentov: Dis. SPb.

4. Veize, A. A. (1985). Chtenie, referirovanie i annotirovanie inostrannogo teksta. M.: Vysshaia shkola.

5. Gavrilov, L. A., \& Latysheva, L. K. (1981). Osnovy referirovaniia i annotirovaniia. $\mathrm{M}$. 
6. Idrisov, F. F. (1987). Obuchenie audirovaniiu original'noi angloiazychnoi razgovornoi rechi pri podgotovke perevodchika-referenta: Dis. M.

7. Leonov, V. P. (1981). O teoreticheskikh osnovakh obucheniia referirovaniiu. Voprosy sovershenstvovaniia bibliograficheskoi podgotovki kadrov. -. Leningrad.

8. Solov'iov, V. I. (1970). Referirovanie v nauchno-informatsionnoi deiatel'nosti i kriterii redaktorskoi otsenki ego soderzhaniia i formy: Dis. M.

Басова Ирина Анатольевна - канд. пед. наук, доцент факультета иностранных языков и регионоведения ФГБОУ ВО «Московский государственный университет им. М.В. Ломоносова», Россия, Москва.

Basova Irina Anatolyevna - candidate of pedagogical sciences, associate professor at the faculty of foreign languages and area studies at the Moscow State Lomonosov University. 